\title{
THE AESTHETIC APPRECIATION OF MUSICAL INTERVALS AMONG SCHOOL CHILDREN AND ADULTS.
}

\author{
By C. W. VALENTINE,
}

Lecturer in Experimental Psychology to the St Andrews Provincial Committee for the Training of Teachers.

\author{
I. The purpose of the experiments. \\ II. The method of experiment with adults. \\ III. The order of popularity of the intervals. \\ IV. The aesthetic effect of the different intervals. Major and \\ minor intervals. The octave. Concords felt as discords. \\ $V$. The method of experiment with school children. \\ VI. Results of the experiments with Elementary School children. \\ VII. Results of the experiments with Preparatory School children. \\ VIII. Comparison of the results of the experiments in the \\ Elementary and Preparatory Schools. \\ IX, Tests for a 'musical ear.' \\ $X$. Introspection of school children. \\ $X I . \quad$ Sex differences in the Elementary School experiments. \\ $X I I$. Summary of results and conclusions.
}

\section{The purpose of the experiments.}

IN 1910 some experiments were begun in order to test the aesthetic appreciation of musical intervals among school children. The object was to discover, if possible, something as to the development with age of a feeling for consonance, and to determine the differences in this respect among children belonging to different cultural groups and having had different degrees of musical training. It seemed desirable also to obtain results from adults, for the sake of comparison.

Apart from this, I wished to ascertain the extent to which individuals could be divided into 'perceptive types' according to their attitude towards musical elements, as $\mathbf{M r} \mathbf{E}$. Bullough has classified 
them in reference to colours ${ }^{2}$, and to note any marked difference between the sexes in reference to their appreciation of musical intervals? ${ }^{2}$.

Further, a great deal of uncertainty still exists as to the order of pleasingness of the twelve intervals playable upon the piano within one octave, though there is of course a general agreement as to which intervals are dissonant and which consonant ${ }^{3}$. Some indeed seem to identify pleasingness with consonance. Others have doubted whether we can isolate an interval so as really to hear it alone, their view being that the pleasingness of an interval will depend not merely upon its degree of consonance, but also on the more or less vague suggestions of other notes. This is of course directly opposed to the assertion that one can isolate an interval and that all consonances are then more pleasing than any dissonances. As to the varying degrees of pleasingness of the intervals one must expect great differences among individuals, though there seems to be a general agreement that to the modern ear the Third is the most pleasing interval, whilst during the middle ages the Fifth was probably the most popular, and with the Greeks, the Octave.

We shall describe the experiments with adults first. The method of experiment with the children was substantially the same.

\section{The method of experiment with adults.}

The subjects of these experiments were university students at St Andrews, or students in the Training College, Dundee. They numbered 146, of whom 84 were women and 62 men. The great majority of the women were Scots: of the men about one quarter were English, one fifth Welsh and the rest Scots. Most of the tests were done with a Chappell piano in excellent condition, the rest upon a new Bechstein, both regularly tuned ${ }^{4}$. The subjects were taken in groups-about 18 in each group on an average. The necessity of perfect silence and absolute independence of judgment was emphasized. All the subjects had undergone a course of experimental psychology and, I think, must have appreciated the importance of guarding against

1 This Journal, II. 406.

2 The discoveries as to perceptive types are not given in this paper. They will be included in a subsequent joint paper by Dr C. S. Myers and the present writer.

3 As to the degree of consonance of the various intervals see C. S. Myers's Text Book of Experimental Psychology, 2nd edition, I. 27.

4 It should be recalled that, owing to the tuning of pianos by the method of "equal temperament,' the intervals (with the exception of the octave) have not their exact theoretic value. 
the slightest amount of suggestion in such experiments. They were provided with paper on which they were asked to record their judgments upon the chords played, stating whether they found them very pleasing, pleasing, slightly pleasing, indifferent, slightly displeasing, displeasing, or very displeasing, adding the reason why, if possible. Each interval was played twice, the notes first being held down for three seconds. Then followed an interval of three seconds' silence, whereupon the notes were again struck and held for three seconds, the periods being timed by a stop watch kept going continuously.

I regret that $I$ had no mechanical means of insuring that all the intervals should be struck with uniform force. But I may add that, though by no means an expert musician, I have been informed by professional musical critics that my touch is accurate and sensitive, having been trained from early boyhood, and judging from the introspective remarks of all the subjects and the answers to specific questions of mine addressed to some taken individually, I believe that I was able to avoid giving any appreciable emphasis to any one note in any of the intervals, and to preserve a fair uniformity in the loudness of the intervals.

In some preliminary experiments I used the notes $c d b, c d$, $c e$, etc. up to the octave $c^{\prime} c^{\prime \prime}$. But as certain observations of subjects revealed preferences based on the pitch of the intervals, I decided that a better arrangement of notes was possible. I was led to distrust the assertion sometimes made that the pitch of a combination of tones is approximately that of the lower of its constituents. One feels diffident in differing from so expert an observer as Stumpf ${ }^{2}$, but my own introspection, and that of several other individuals specially tested, suggests that the pitch of the higher note in any combination near the centre of the piano is likely to be an influential determinant of the apparent pitch of the combination. I gave to several subjects the test suggested in this connexion by Stumpf. They were asked whether $c^{0} c^{\prime}$ or $c^{\prime} c^{\prime \prime}$ differed the more from $c^{\prime}$. Stumpf asserts that the lower octave differs more, thus confirming, he says, his assertion that $c^{0}$ gives the pitch of $c^{0} c^{\prime}$. I put this test to twelve subjects, and nine of them asserted most emphatically the opposite to what Stumpf says. Eleven of the twelve

1 Even if one note is slightly louder than another in an interval, it does not, according to Stumpf, affect the consonance of the interval (Beitr. zur Akustik und Musikwissenschaft, II. 10, quoted in Lalo's Esquisse d'une Aesthetique Musicale). But of course there might be some difference in the feeling effect of the interval, even though the fusion were not changed.

2 Tonpsychologie, 2te Aufl. II. 384. 
also asserted that $g^{0} g^{\prime}$ appears higher in pitch than $b^{0} d \#$, though the fundamental of the former is two tones lower than that of the latter. This suggests that the pitch of an interval appears (for most people) to be nearer that of the higher of its component notes rather than the lower. It seems to me possible that owing to his exceptional musical capacity and training there is a much stronger tendency for Stumpf to refer every interval to its fundamental tone than is the case with the average individual, thus bringing the fundamental into greater prominence in the field of attention. Hence its greater influence in determining the apparent pitch of the interval'.

Had I performed all the above tests before conducting my experiments I might have felt inclined to keep the upper tones of all the intervals always the same, or I might at least have let them vary in pitch less than the lower tones. As it was, I resolved upon a compromise, choosing the following series of notes to represent the various intervals,

$$
\begin{array}{ll}
\text { minor second, } & c^{\prime} d b, \\
\text { major second, } & c^{\prime} d^{\prime}, \\
\text { minor third, } & b^{0} d^{\prime}, \\
\text { major third, } & b^{0} d \sharp, \\
\text { fourth, } & b b e b,
\end{array}
$$

and so on, alternately raising the upper note or lowering the lower a semitone until for the octave we get $g^{\circ} g^{\prime}$. Thus the mean between the two notes in any interval would always be $c^{\prime}$ or $c \#$, or some note between these.

It was for the sake of the children in the main that this arrangement was made, for it was surmised, rightly as it proved, that they would be much more influenced by absolute pitch than would the adults. That the new arrangement was justified is, I think, shown by the following fact. As in the case of the adults, the children were asked to give their reasons for liking or disliking an interval, and a fairly frequent reason was that the notes were 'nice and high,' or ' too low.' Now it appears that such votes given by the children for an interval "because it is nice and high (or low)" are fairly equally scattered over the various chords, and that judgments against intervals because they are high (or low) are also similarly scattered. The evidence indeed (in

1 Two of the three exceptions who agreed with Stumpf with regard to the first test were highly trained musicians. With one of these subjects the nature of the intervals compared seemed to have some influence upon the apparent pitch. Thus $c^{\prime} g^{\prime}$ was judged higher than $d^{\prime} f^{\prime}$, but $g^{0} f^{\prime}$ was judged lower than $b^{0} d \sharp$. 
so far as the reasons given by such young children can be trusted) tends to support the view I have put forward that the higher note is more influential than the lower in determining the apparent pitch of an interval. Thus the following table, giving the judgments of children from eight years to thirteen inclusive, shows that the third $b d \#$ is judged to be 'low' more often than the octave $g^{0} g^{\prime}$, and 'high' less often than the octave, presumably because the upper note of the third is lower than the upper note of the octave.

\section{TABLE I.}

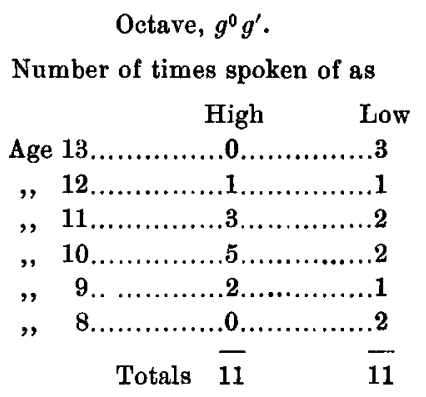

Major third, $b^{0} d \sharp$.

Number of times spoken of as

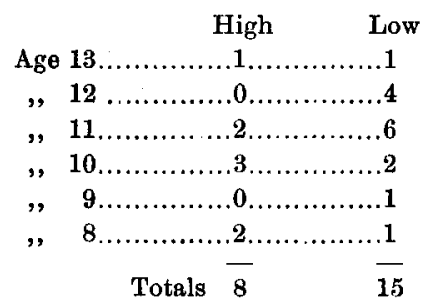

Before each sitting the intervals were arranged in a haphazard order, care only being taken that an interval should not appear often in the same position, and also that the same succession of two pairs should not recur. The twelve intervals were then played in the order arranged, time being given after each for the subjects to write their introspective remarks at once. After the twelve had been given, some easy tests of musical capacity such as have been used by Stumpf were given $^{1}$, and then the twelve intervals were played over again in the reverse order to the first, in order to distribute equally among the intervals any effects due to familiarity, etc., and to equalise as far as possible the effects of contrast due to the chord preceding the one played. As they were thus arranged in about twenty different orders for the adults, probably the various effects of contrast were fairly scattered. The likelihood of such disturbing effects was further lessened

1 The subjects had to say whether one or two notes were being played on the piano, and which of two successive notes, separated by a tone or semi-tone, was the higher. This proved so easy for most of the adults that I did not attempt any division of the students on the basis of the results. Only about half a dozen students could be reckoned as ' unmusical' upon the basis of the tests. The same tests were performed on the children; for the results see page 210 . 
by the long interval allowed for the writing of introspective remarks. But observations made by some subjects show that one cannot hope to get rid of them entirely.

\section{The order of popularity of the intervals.}

On the basis of the judgments expressed by the subjects, the intervals can be arranged in order of popularity. In reckoning the scores of the various intervals the following values were assigned. For 'very pleasing' 2 , 'pleasing' 1 , 'slightly pleasing' $\frac{1}{2}$, 'indifferent' 0 , 'slightly displeasing' $-\frac{1}{2}$, 'displeasing' -1 , 'very displeasing' -2 . This scale gives the following results for all the 146 adult subjects.

\section{TABILE II.}

$\begin{array}{llll}\text { Major third } & \ldots & \ldots & \mathbf{3 2 4} \\ \text { Minor third } & \ldots & \ldots & \mathbf{2 6 1} \\ \text { Octave ... } & \ldots & \ldots & \mathbf{2 4 6} \frac{1}{2} \\ \text { Major sixth } & \ldots & \ldots & \mathbf{2 4 3} \\ \text { Minor Sixth } & \ldots & \ldots & 214 \\ \text { Fourth ... } & \ldots & \ldots & 157 \frac{1}{2}\end{array}$

$\begin{array}{lllc}\text { Tritone } & \ldots & \ldots & 153 \\ \text { Fifth ... } \ldots & \ldots & 1391 \\ \text { Major second... } & \ldots & -99 \\ \text { Minor seventh } & \ldots & -\mathbf{1 6 2} \\ \text { Major seventh } & \ldots & -\mathbf{3 1 6} \\ \text { Minor second } & \ldots & -\mathbf{3 6 8}\end{array}$

Of course we cannot assume from this list that the major third was the most pleasing and the minor second the least pleasing of the intervals to all subjects. In some cases it was obviously not so. We can only say that on the average the major third is the most pleasing ${ }^{1}$.

As will readily be seen, the order is very far from that of degree of consonance. The major third scores much more highly than the octave, both the thirds and both the sixths score higher than the more consonant fourth and fifth, and even the tritone-which has been reckoned on the border line between consonants and dissonants, is found more pleasing on the average than the fifth-the most consonant of all the intervals except the octave. The degree of consonance then is by no means coincident with the degree of pleasingness.

If the votes of men and women are separated we get the following results :

1 Theoretically it is of course possible that an interval-say the fourth-owes its intermediate position merely to the fact that some subjects like it most and others dislike it most. As a matter of fact no interval showed such results. A decreasing number of 'very pleasing' judgments goes with a decreasing number of 'pleasing' and an increasing number of 'indifferent' and of 'displeasing' judgments. 


\section{The Appreciation of Musical Intervals}

TABLE III.

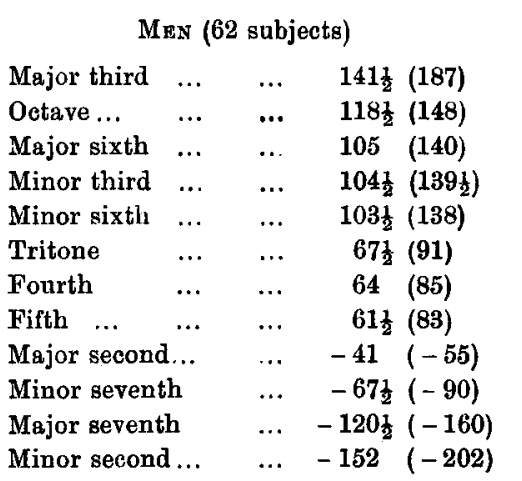

WoMEN (84 subjects)

$\begin{array}{lllll}\text { Major third } & \ldots & \ldots & \ldots & 183 \frac{1}{2} \\ \text { Minor third } & \ldots & \ldots & \ldots & 156 \frac{1}{2} \\ \text { Major sixth } & \ldots & \ldots & \ldots & 138 \\ \text { Ootave ... } & \ldots & \ldots & \ldots & 128 \\ \text { Minor sixth } & \ldots & \ldots & \ldots & 110 \frac{1}{2} \\ \text { Fourth ... } & \ldots & \ldots & \ldots & 93 \frac{1}{2} \\ \text { Tritone } & \ldots & \ldots & \ldots & 86 \\ \text { Fifth ... } & \ldots & \ldots & \ldots & 78 \\ \text { Major second } & \ldots & \ldots & \ldots & -58 \\ \text { Minor seventh } & \ldots & \ldots & -95 \\ \text { Major seventh } & \ldots & \ldots & -196 \\ \text { Minor second } \ldots & \ldots & \ldots & -216 \frac{1}{2}\end{array}$

The numbers in brackets represent the votes of the men increased proportionately to make them comparable with those of the women.

In view of the great variations in the preferences of different individuals, there is no very striking difference between these two orders with the exception of the greater popularity of the octave and the minor sixth among the men, and of the minor third among the women.

\section{The aesthetic effect of the different intervals.}

The introspective remarks throw some light upon the nature of the effects produced by the various intervals. We will consider them in order of their popularity.

Major third. A great variety of reasons are given for liking the major third. It is described as harmonious, melodious (frequent), something like the previous chord (which was an octave and was liked), well balanced, blending, mellow, soothing (frequent), calm, sad (frequent), solemn, minor, feeling of anticipation, melancholy, firmness tinged with pleading, strong. Associations with the major third are solemn music, church bell, Dead March in Saul (frequent), Amen in church. Reasons for disliking the major third slightly, or finding it indifferent, are the following: unfinished, feeling of lethargy, slightly too solemn, Dead March in Saul suggested. The major third was disliked only four times, in each case by a woman and either because it was too sad, or meaningless.

Minor third. Very varied reasons are given for liking the interval. Comments include the following: soothing, mournful, solemn, suggests Dead March, refined, cheerful, dreamy. 
It is only disliked seven times, the great drop in the score (compared with the major third) being due to the comparative frequency of the judgment ' indifferent.'

Major and minor intervals. The question has been discussed as to whether the effects of major and minor keys are 'inherent' in the intervals themselves, i.e. whether the major chord strikes some essentially cheerful, responsive note in our nature, the minor rousing equally 'naturally' a sad feeling; or whether the different effects of the two keys are due merely to association. If the latter we must suppose that the custom of setting sad songs to minor keys originated without any felt suitability of the key to the ideas, but that gradually, by repetition of the association, we have come to connect the two, so that a piece of music in a minor key now appears to us sad or plaintive. In favour of the latter view we have the fact that in some civilised countries the major key is frequently used for sad songs and the minor sometimes for quite cheerful or even merry ones. Thus we find dance music and even comic songs set to a minor key. Further, it is asserted that the music in the minor key played by some primitive peoples, while sounding sad and dirge-like to us, does not appear to be so to the natives'.

The results of the present series of experiments, as summarised in the following table, certainly suggest that there is, inherently or through association, no more sadness in the minor third or minor sixth than in the major third or major sixth.

Table IV. Number of times interval is described as sad or plaintive.

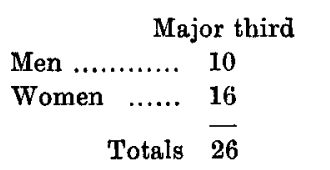

Minor third
5
$\frac{6}{11}$

Major sixth
16
$\frac{11}{27}$

Minor sixth
7
$\frac{7}{14}$

The figures show that the major intervals are described as sad or plaintive twice as often as the minor. Of course we must remember that we are only testing the effect of one interval, and that, too, with the notes played simultaneously, whereas in a piece of music in the minor key we should also have the intervals given by consecutive notes. Further, their relation to the scale as a whole is brought out more fully in a piece of music and this is doubtless the most important point in determining the impression made by the music. The recognition of the key as minor however is not necessary for the effects of sadness and

1 Cf. Müller-Freienfels, Psychologie der Kunst, Ir. 70. 
plaintiveness, for these may be felt by persons who are quite ignorant of the distinction between major and minor keys. It is noteworthy that five times the major third was actually described as minor while the minor was never called 'minor.' Probably this particular major interval was felt to be 'sad' and was termed 'minor' because of the familiar association of the two in music.

Even when a third note is added in these experiments and the chords $c e g$ and $c e^{b} g$ are played, the major chord is still termed sad as frequently as the minor, though judging from his own introspection, the present writer is greatly surprised at this result. Thus among about forty adults to whom these chords were played (among twenty other chords), eight persons described the major chord and six persons the minor chord as sad.

The evidence, then, of these experiments is that the minor intervals (when the notes are played simultaneously) are not felt as sad even to the same extent as the major intervals. And this is in favour of the view that the general significance of the minor key for modern European ears is not due to an effect inherent in the relation of the notes in a minor interval, but is more probably the effect of association. Further, for the average person it seems that more is necessary as a basis for this association than isolated minor intervals or chords.

The octave. The octave is often termed indifferent and is disliked more frequently than the minor third. It is found by some too tame, dull, thin and skimpy, lacking in meaning, whilst others are attracted by its clearness, smoothness, idea of no hindrances, or describe it as bold, bright, strong and cheerful, giving the feeling of rest.

We saw that the octave was considerably more pleasing to the men than to the women, and we find that only one man among 62 judged it positively displeasing, while 15 women among 84 do so. The introspective remarks give us a clue to an interesting sex difference

1 In these trichord (Dreiklänge) experiments the chords had always $c^{\prime}$ as the tonic. This fact precludes an explanation that might conceivably be put forward as to why the major is described as sad, or even as minor, in the interval experiments, viz. that sometimes the influence of the preceding interval might determine that a major interval should appear as part of a minor scale. For example, when $a^{b} b^{b}$ is followed by $c b b$, if the tonic $a^{b}$ were still held in mind when $c^{b} b$ was played (which would be after an interval of 2 or 3 minutes) and if $c^{b} e^{b}$. were then heard as in the key of $a^{b}$, the $c^{b}$ might give, with the retained impression of the $a^{b}$, the impression of the minor third of the scale $a \dot{b}$. This seems to me extremely unlikely in view of the long time between the playing of the intervals and also in view of the fact that very few of my subjects were even average musicians. Further the major third usually followed intervals which could not produce such an effect. In any case, the experiments with the trichords were free from even this remote possibility. 
here. Whereas the men frequently like it because it is strong, firm, bold, suggesting majesty and force, this aspect of the octave does not appeal in the same way to the women; it is even displeasing to some of them, who speak of it as too assertive, hard, or harsh.

The major and minor sixths. Coming to the next intervals in order of preference, one is immediately struck with the enormous individual differences which now show themselves. Thus of four persons listening to the major sixth at the same time, one speaks of it as 'soothing,' the second as 'rousing,' the third as 'sentimental,' and the fourth even as 'jarring to the ear.' This is generally characteristic also of the fourth, tritone and fifth. A distinct tendency however is noticeable for the sixths to be felt as sad or solemn. Here for the first time we find suggestions of disharmony, half a dozen or more subjects finding that the notes do not blend satisfactorily, a remark which applies also to the fourth, fifth and tritone.

Fourth and fifth. The low position of these intervals is not traceable, on the basis of the introspective remarks, to any definite disagreeableness in them. The average value of the votes, it will be seen, yields for each of them nearly 0.5 , the equivalent of 'slightly pleasing.' But they rarely become 'very pleasing' and are often judged 'indifferent,' sometimes with the description 'ordinary,' 'no impression.'

It is very remarkable that these-the three most consonant intervals after the octave-are sometimes spoken of as discords, or as lacking in harmony, oftener indeed than the tritone ${ }^{1}$. Possibly we have here a suggestion that the conventional concord may come to appear less consonant by becoming for some reason very unpleasant (perhaps from appearing, first commonplace, and then monotonous). On the other hand there is ample introspective evidence that dissonant intervals, where pleasing, are sometimes felt as consonant. This is probably the case when they are introduced appropriately in musical compositions. But the above statement is not confined to the cases where the discords are heard as leading to a pleasant resolution. The impression occurs too when they are heard alone.

As to the four discords we may further remark that any one of them may appear pleasing through some definite association or symbolic suggestion, and that sometimes discords are liked as a pleasant change from a preceding harmonious interval.

I It is possible that some of these judgments may be due to the fact that the fourth and fifth are somewhat out of tune as sounded on the piano. But at least one subject who repeatedly gave such judgments was distinctly weak in detecting dissonances. 


\section{The method of experiment with school children.}

These experiments were performed on one hundred and ninety-five boys and girls from two Elementary Schools in Dundee, between the ages of six and fourteen, and upon seventy-six girls between the same ages in a high class Preparatory School in St Andrews'.

The object, as already stated, was to discover if possible something as to the development with age of a feeling for consonance, and the difference in this respect between children belonging to different cultural groups and differing with respect to musical training. There are, of course, enormous individual differences even among children as regards the sensitivity to music. By means of these tests one could only hope to study the averages of a large number of children groups of which differed in culture and age.

The method of procedure was the same as in the experiments with adults, with the following exceptions. I played all the intervals over to the children before the judgments on each interval were given, in order to show them the kind of test they were to expect. During the latter half of the experiments I also added a new interval (ninth) with which I always began the list, though the judgments on it were ignored.

In the case of the Elementary School children I had the cooperation of some of my own students, partly because many of the children were too young to be trusted to make satisfactory written records, and partly in order that the students might have some experience of research work. The Elementary School children were taken in twelve groups of about fifteen pupils, of various ages, at a time. Thus the intervals would be played in twenty-four different orders in the course of the experiments, a new arrangement being made for each group, and the exact reverse of it also being used at each sitting.

The children were distributed over a large room, and a child was allotted to each student, who recorded the child's judgments. All the students had had some training in experimental psychology. The method and purpose of the experiments were carefully explained to them beforehand. I impressed upon them especially the supreme importance of giving no sign of approval or disapproval of the child's judgments, and of avoiding any possible suggestion. At each test I explained the experiment to the children somewhat as follows. "I am going to ask you to listen carefully while I play some notes on the

1 In a few cases the same pupil returned for the test again a year or so later. In these cases they are reckoned twice in counting the number of children. 
piano, and then to say whether you like them or not. If you can, say why you like them or don't like them. I want you to say exactly what you think. No one will see your answers except myself. You are not in school now, and no one will blame you for what you say." A little friendly talk soon seemed to put the children at their ease. The students were told to say nothing that was not absolutely necessarywhich practically reduced itself to asking 'why' of those children who seemed to need encouragement to state their reasons. As I had all the students in full view I was able to see that this rule was remembered. We know from our experiments on the adults the average order of preference for the intervals with the students. Thus if there were any influence of suggestion on the part of the students we know in which direction it is likely to work. Personally I believe that in these experiments such influences were extremely small.

Such collective experiments have grave dangers and disadvantages unless very carefully carried out; but apart from the fact that they enable one to examine far more subjects than would otherwise be possible, they may, I think, have two advantages. In the first place the children seem more at their ease when a large group of them is examined simultaneously than when only one child is tested at a time. Further, each group of children included children of various ages from six to thirteen, and both boys and girls. Thus if any irregularity did occur (as for example if an interval were played somewhat more softly than usual), its effect, if any, would be distributed over children of all ages.

A more serious difficulty was to prevent the children from being influenced by what they heard other children saying. In view of this they were separated as far as possible, and were instructed to whisper and to say ' $I$ like it' or ' $I$ don't like it' instead of 'yes' or 'no,' for 'yes' was likely to be heard by others near, even when whispered. Generally this rule was obeyed well, but very occasionally a faint 'yes' was audible." Here again however we know something of the likelihood of the effects of suggestion, if such there were. Seeing that the youngest children are more subject to suggestion than the older ones, they would be more likely to adopt the answers of their seniors than vice versa, and thus would tend to raise the apparent degree of development of the juniors. As will be seen, this possibility only makes some of the later observations more significant. The question as to whether the youngest children completely understood what they had to do will be discussed later. I may say here that though one or two of the 
youngest children did not give any answer with respect to some of the intervals, none of the answers given were foolish in the sense of being inapplicable, i.e. they were always judgments as to whether they liked the notes or not. In very few cases was the answer ' $I$ don't know' given-indeed it might have been more encouraging if this answer had been given more often.

\section{Results of the experiments with the Elementary School children.}

An interval scored +1 when the judgment ' $I$ like it' was given, -1 for the judgment ' I don't like it.'

In Table $\mathrm{V}$ are given the votes of the children of various ages for the different intervals. As the numbers of children of the various ages were unequal, the votes are adjusted to make them represent proportionately the judgments of thirty children of each age, for the sake of easy comparison. The intervals are arranged in their order of preference, as determined by adults. For the sake of comparison a column is added showing the votes given to the intervals by the 146 adults, reduced to represent the votes of thirty individuals.

TABLE V. Showing average votes for thirty individuals of all ages.

As each child judged each interval twice, the highest possible score for any interval is +60 and the lowest possible -60 . But these figures do not apply to the adults owing to greater variations of judgments which were permitted to them [e.g. very pleasing +2 , very displeasing -2 , slightly pleasing $+\frac{1}{2}$, and so on].

\begin{tabular}{|c|c|c|c|c|c|c|c|c|c|}
\hline Age in years .............. & 6 & 7 & 8 & 9 & 10 & 11 & 12 & 13 & Adults \\
\hline Actual no. of children ... & 15 & 24 & 25 & 27 & 27 & 24 & 22 & 31 & \\
\hline 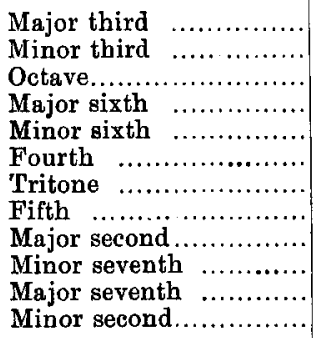 & $\begin{array}{l}36 \\
38 \\
26 \\
20 \\
32 \\
34 \\
28 \\
22 \\
32 \\
24 \\
28 \\
16\end{array}$ & $\begin{array}{l}37 \\
35 \\
29 \\
22 \\
36 \\
35 \\
40 \\
41 \\
42 \\
30 \\
35 \\
30\end{array}$ & $\begin{array}{l}44 \\
35 \\
37 \\
35 \\
36 \\
26 \\
28 \\
35 \\
20 \\
40 \\
26 \\
20\end{array}$ & $\begin{array}{r}36 \\
42 \\
42 \\
42 \\
29 \\
36 \\
33 \\
22 \\
16 \\
28 \\
21 \\
4\end{array}$ & $\begin{array}{r}33 \\
38 \\
31 \\
31 \\
33 \\
36 \\
23 \\
29 \\
6 \\
18 \\
9 \\
4\end{array}$ & $\begin{array}{r}41 \\
36 \\
42 \\
40 \\
25 \\
37 \\
17 \\
35 \\
9 \\
0 \\
-20 \\
-\quad 5\end{array}$ & $\begin{array}{r}35 \\
20 \\
22 \\
28 \\
28 \\
25 \\
5 \\
0 \\
-11 \\
3 \\
-20 \\
-35\end{array}$ & $\begin{array}{r}37 \\
25 \\
31 \\
32 \\
37 \\
-2 \\
12 \\
11 \\
-5 \\
2 \\
-25 \\
-32\end{array}$ & $\begin{array}{r}36 \\
29 \\
27 \\
27 \\
24 \\
17 \\
17 \\
15 \\
-11 \\
-18 \\
-35 \\
-41\end{array}$ \\
\hline Av. score of 8 concords... & $27 \cdot 0$ & $33 \cdot 1$ & $34 \cdot 5$ & $35 \cdot 0$ & $\mathbf{3 1} \cdot 7$ & $33 \cdot 5$ & $20 \cdot 4$ & $22 \cdot 9$ & $24 \cdot 0$ \\
\hline$, \quad, \quad 4$ discords.. & $25 \cdot 0$ & $35 \cdot 6$ & $26 \cdot 5$ & $17 \cdot 0$ & $9 \cdot 2$ & $-4 \cdot 0$ & $-15 \cdot 8$ & $-15 \cdot 0$ & $-26 \cdot 2$ \\
\hline
\end{tabular}


An inspection of Table $\mathrm{V}$ shows that there is no consistent preferences for consonances over dissonances at the ages of six and seven. With the six-year-olds two of the discords are liked more than the octave, and three of them are liked more than the fifth or the major sixth. At seven years all the discords are liked better than the octave or minor sixth.

Of course one cannot infer that there is no capacity at this age to discriminate between a discord and a concord. There may be a differcnce of sense experiences in the case of these children which corresponds to the different experience we have in the consonances and dissonances. It is more than likely that the well-known love of children for noise of any kind keeps in the background any tendency to dislike a discord as such $^{1}$. Indeed, their love of sound for its own sake may act in favour of discords. For as Stumpf has shown, dissonant intervals often appear to children as containing three, four or even five notes, apparently giving a greater body of sound, and even to adults they are generally more stimulating, in a sensational way, than are consonant intervals.

We can, however, at least infer that at this age these children had not such unpleasant sensations produced by discords as to diminish appreciably their pleasure in the sound as sound.

There remains the difficulty as to whether the children really understood what they had to do. But surely the question 'Do you like that?' should be intelligible to the average child of six or seven if there is any definite feeling of pleasure or displeasure produced. Where there is precocious development of musical sensitivity, children are able at an even earlier age than this to express very definite and decided judgments upon intervals and chords, as in the case quoted by Stumpf, of a five-year-old boy who could 'sing seconds' to a melody with ease, and who always gave an immediate judgment in favour of the major trichord as compared with the minor, whichever was played first". 'The fact that occasionally a child would say 'I like it' (or still more rarely 'I don't like it') to almost every interval, might appear to indicate a lack of comprehension as to what was being done; and this may have been the case with a few of the least intelligent pupils. But it seems quite possible that even in these cases the uniformity of judgments signifies an inability to appreciate the contrast between

1 Cf. Dr Myers's remarks upon the dangers of inferring that some primitive tribes have no feeling for consonance because they disregard it in their mnsic. "The Ethnological Study of Music," in Anthropolngical Essays presented to E. B. Tylor, Oxford, 1907, 239.

2 Tonpsychologie, II. 378. 
consonances and dissonances; for series of judgments, all of them 'pleasing,' were also given by children of ten, eleven, twelve and thirteen years, and such series can hardly be ascribed to incapacity to understand at this age.

Nor do the more intelligent children show any greater antipathy to the discords than do the less intelligent'. Unfortunately the numbers are very small when one comes to divide the children of each year into intelligent and unintelligent. But I may state that the average score for the four discords among twenty-two 'intelligent' children of six or seven years of age was 0.5 , that of the concords being $0.6^{2}$. For eight comparatively unintelligent children the scores were as follows : discords $0 \cdot 65$, concords 0.7. Among the eight-year-olds, indeed, it was the thirteen unintelligent children who showed a preference for the concords, the seven intelligent ones showing a slight preference for the discords. Thus there is no evidence that, with these children, capacity to understand the simple requests made of them was the main factor in determining the trend of the scores, or, indeed, that it had any such influence whatever ${ }^{3}$.

If we take the children individually, we find that none of the sixand seven-year-olds give even one judgment of dislike to each of the four discords without also giving such judgments freely among the concords, including the octave. At eight years, however, we find two children who only give three of eight possible votes of approval to the discords, but give respectively fourteen and thirteen (of sixteen possible) to the concords.

At nine years of age we find a great advance. At least seven children,

1 My best thanks are due to Mr J. Williamson, Headmastex of South Tay Street School, Dundee, for the care he took in personally classifying all the children in his school who underwent these tests. In cooperation with the class teachers he divided them into three groups, 'intelligent,' ' moderate,' and 'weak.' Owing to the smallness of the last group they are reckoned with the 'moderates.' I did not obtain such a classification from the other school from which the children were taken, chiefly because of the impossibility of making sure that the same standard of intelligence was being used as a basis of division; moreover, the number from the second school was too small to make separate calculation of any value.

2 The proportions of intelligent and unintelligent children were approximately equal for both these ages.

3 There is on the other hand no absolute proof to the contrary: it might still be the case that the task was so much above the powers even of the most intelligent eight-year-old children that even their superior intelligence would not be of any value to them or cause any contrast between their results and those of the less intelligent. But this seems highly improbable. 
out of twenty-seven, showed a marked and consistent preference for the concords before the discords. Their totals are:

'Pleasing' judgments given upon four discords, 16

$$
\text { " " " eight concords, } 93 .
$$

This great advance at the age of nine is also reflected in the totals for all the nine-year-olds, the average score of the discords being now only one-half that of the concords.

Summing up, then, we may say that, on the evidence of 936 votes, no preference for concords before discords is shown by the six- and seven-year-old children; that a slight preference for the concords begins to appear among a few of the eight-year-old children, calculated on a basis of 600 votes; and that at nine years old the preference for concords is decided. It is interesting to note that $\mathrm{Mr} \mathrm{J}$. A. Gilbert as a result of his experiments on "The Musical Sensitiveness of School Children"," concluded that in the discrimination of tones varying in pitch, the average school child improves more than twice as fast from six to nine years, as it does in the years from nine to nineteen.

At the age of ten the discords become still less pleasing, and at eleven they have a negative score for the first time, though the score of the concords is practically as high as ever. At twelve and thirteen the children become much more critical in their attitude both towards the discords and to those concords which were found to be least liked by the adults, viz. the fourth, the tritone and the fifth. In regard to intervals about which adults have been seen to differ so much in their judgments, one cannot expect a perfect regularity of change in the votes of the children with increasing age. But on the whole we may say, judging from Table $\mathrm{V}$, that no marked and continued preference is shown for any of the concords, and none of them is conspicuously less pleasing than the average, until we come to the ages of ten and eleven, where the lesser consonance of the tritone seems to have its effect upon the children. At twelve and thirteen, however, we suddenly find a comparative indifference to the highly corsonant fifth and fourth, similar to what was found with adults. This is shown in Table VI, where the scores of six- and seven-year-old children are added together, and also those of eight and nine and so on, and then reduced to represent the votes of thirty children. The votes of the men and women are also given, adjusted so as to make the votes given for the most pleasing interval approximately the same as the children's vote.

\footnotetext{
1 Studies from the Yale Psychological Laboratory, 1892-3.
} 
TABLE VI. Showing average votes for thirty individuals.

\begin{tabular}{|c|c|c|c|c|c|c|}
\hline Ages $\ldots \ldots \ldots \ldots \ldots \ldots$ & 6 and 7 & 8 and 9 & 10 and 11 & 12 and 13 & Men & Women \\
\hline Major third ......... & 36 & 40 & 87 & 36 & 35 & 37 \\
\hline Minor third ......... & 36 & 38 & 37 & 22 & 20 & 31 \\
\hline Octave .............. & 27 & 39 & 36 & 26 & 30 & 26 \\
\hline Major sixth & 21 & 38 & 35 & 30 & 26 & 28 \\
\hline Minor sixth ........ & 34 & 32 & 29 & 32 & 26 & 22 \\
\hline Fourth .............. & 34 & 31 & 36 & 11 & 16 & 19 \\
\hline Tritone $\ldots \ldots \ldots \ldots \ldots$ & 34 & 30 & 20 & 8 & 17 & 17 \\
\hline Fifth ................. & 31 & 28 & 32 & $\check{\delta}$ & 15 & 16 \\
\hline Major second & 37 & 18 & 7 & -8 & -10 & -12 \\
\hline Minor seventh ...... & 27 & 34 & 9 & 2 & -17 & -19 \\
\hline Major seventh ...... & 31 & 23 & -5 & -22 & -30 & -39 \\
\hline Minor second ...... & 23 & 12 & o & --33 & -38 & -43 \\
\hline
\end{tabular}

By the age of twelve or thirteen then, these children have reached a stage at which their preferences for the various intervals are remarkably like those of the men and women. The major and minor thirds, the octave, and the two sixths form the 'most pleasing' group, both for these children and for the adults, the major third leading in all three columns. The fourth, fifth and tritone form a group of 'less pleasing' (but still 'pleasing') intervals, while the discords all have minus scores except the minor seventh which just secures +2 . It is curious that this interval is the most pleasing (or least displeasing) of the discords for children from the age at which any discrimination between concords and discords takes place, while for the adults the major second is preferred of the four discords.

\section{Results of experiments on Preparatory School children.}

Table VII shows the results of the experiments in the girls' Preparatory School. These children wrote their own judgments on paper, with the exception of one or two of the very youngest, for each of whom one of the teachers did the writing. They were taken in four groups of about eighteen each, including children of various ages. In a few cases the children modified their judgments by 'very,' etc., saying 'very pleasing' (or 'displeasing') or 'slightly pleasing' (or 'displeasing '), for which the scores of $1 \frac{1}{2}$ (or $-1 \frac{1}{2}$ ) and $\frac{1}{2}$ (or $-\frac{1}{2}$ ) were awarded. These children took a very keen interest in the tests, and most of them, even the very youngest, seemed very decided in their judgments. 
Table VII. Preparatory School Results. Showing average votes for thirty individuals of all ages.

\begin{tabular}{|c|c|c|c|c|c|c|c|}
\hline Ages .... & $6 \& 7$ & 8 & 9 & 10 & 11 & 12 & $13 \& 14$ \\
\hline Actual no. of children... & 7 & 10 & 11 & 10 & 9 & 15 & 14 \\
\hline Major third & 45 & 57 & 52 & $43 \frac{1}{2}$ & 56 & 56 & 43 \\
\hline Minor third . & 45 & 40 & 30 & 54 & 53 & 51 & 44 \\
\hline Octave ........ & 4 & 45 & 14 & $49 \frac{1}{2}$ & $41 \frac{1}{2}$ & 50 & 52 \\
\hline Major sixth. & 17 & 45 & 36 & $33^{2}$ & $51 \frac{1}{2}$ & 40 & 43 \\
\hline Minor sixth ................. & 0 & 42 & 18 & 39 & $41 \frac{1}{3}$ & 45 & 25 \\
\hline Fourth .................... & 40 & 42 & 3 & 18 & $7 \frac{1}{5}$ & 30 & 26 \\
\hline Tritone & -13 & 33 & 17 & 21 & $2+\frac{1}{2}$ & 26 & 11 \\
\hline 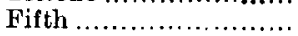 & 10 & 39 & $1 \frac{1}{2}$ & 6 & 8 & 38 & $7 \frac{1}{2}$ \\
\hline Major second ............... & $-\mathbf{3 4}$ & -18 & $-47^{2}$ & $\ldots 30$ & -50 & -10 & $-43^{2}$ \\
\hline Minor seventh ............ & 6 & $\begin{array}{l}24 \\
\end{array}$ & -44 & -36 & -23 & -30 & $1-36$ \\
\hline Major seventh ............... & -38 & -24 & -58 & -42 & -60 & -58 & $-\overline{53}$ \\
\hline Minor second $\ldots . . . . . . . . .$. & -21 & $-4 \tilde{j}$ & -60 & -54 & $-61 \frac{1}{2}$ & -60 & -58 \\
\hline
\end{tabular}

N.B. As these children had permission to say 'very pleasing' and 'very displeasing' (scoring $+1 \frac{1}{2}$ and $-1 \frac{1}{2}$ respectively) the maximum and minimum scores for each interval are +90 and -90 respectively, instead of +60 and -60 , as was the case with the elementary children.

The scores are raised to represent proportionate numbers for thirty children in each column for the sake of comparison between the different ages and with Table $\mathrm{V}$.

It will be seen at once that we have strikingly different results from those given in Table $V$. At eight years of age, and even at six and seven, the discords are already discriminated and all have minus scores, with the exception again of the minor seventh, which, as with the Elementary School children, retains its power to please longer than the other discords. By the age of nine we have preferences very similar to those of the adults, and such as are not given by the Elementary School children before the ages of twelve and thirteen, viz. the major third leading, the fourth and fifth low, and all the discords with negative scores.

Of course, seeing that the intervals were only presented twice to each subject, the numbers of children are very small on which to base any conclusion, and some variations occur which we might expect under the circumstances. From the first, however, a marked antipathy to the discords is shown. Possibly for a thoroughly reliable average we require a number given by the addition of not less than three of the columns of 
Table VII. But an order of preference remarkably like that of the adults is given either by adding the eight- and nine-year columns or those of the nine- and ten-year-olds, as is shown in Table VIII.

\section{Table VIII.}

Cuildren of 8 or 9 years.
1. Major third.
2. Major sixth.
3. Minor third.
4. Minor sixth.
6. Tritone.
7. Fourth.
8. Fifth.
9. Minor seventh.
10. Major second.
11. Major seventh.
12. Minor second.

Adults.

1. Major third.

2. Minor third.

3. Octave.

4. Major sixth.

5. Minor sixth.

6. Fourth.

7. Tritone.

8. Fifth.

9. Major second.

10. Minor seventh.

11. Major seventh.

12. Minor second.
Children of 9 or 10 years.

1. Major third.

2. Minor third.

3. Octave.

4. Minor sixth.

5. Major sixth.

6. Tritone.

7. Fourth.

8. Fifth.

9. Minor seventh.

11. Major second.

11. Major seventh.

12. Minor second.

\section{Comparison of the results of the experiments in the Elementary and Preparatory Schools.}

Table VIII shows that the Preparatory School children at about the age of nine show a resemblance to the adults in their liking for the different intervals, which is only shown at the age of thirteen by the Elementary School children.

This great difference must be attributed presumably to one or more of the following grounds: (i) greater intelligence, (ii) greater inherited sensitivity to music, (iii) much earlier and more thorough instruction in music and closer familiarity with good music. We have good grounds for disbelieving that general intelligence has much to do with the results of these music tests. The absence of any consistent difference between the judgments of the more intelligent and the less intelligent of the six-, seven- and eight-year-old children in the Elementary School has already been mentioned (p.204). Among the older children also there is absolutely no regular tendency for the intelligent children to approximate to the adult standard any more than the unintelligent do.

Doubtless, then, one or both of the last two causes mentioned are responsible for the difference between the Elementary and Preparatory School children. Unfortunately these experiments do not afford decisive evidence as to which is the chief cause. After the age of seven practically every girl in the Preparatory School learned some musical 
instrument, and they all often heard good music ${ }^{1}$. Many of the older children had been learning music for five or six years; while among the Elementary School children only four boys and eleven girls had had any lessons on the piano, and two (girls) on the violin. Thus the difference in musical training among the two sets of children is enormous. As to how far this is accompanied by greater inherited musical capacity it is difficult to say, but it seems to me probable that this latter has comparatively little to do with the observed differences between the two types of schools. The comparative ease with which the children of the upper classes, as compared with those of the lower, take to music, even if clearly demonstrated, would not help us in deciding the relative importance of heredity and training, for the former have already been more accustomed to hear good music than the latter.

Both Prof. Spearman and Mr Burt found that children of more cultured families had greater powers of pitch discrimination than those of less cultured families, the average thresholds in two Preparatory Schools being little more than half those attained from Elementary School children, a difference which it was shown could not be attributed to practice?

We are, I believe, ignorant of the extent to which sensitivity of pitch discrimination affects the aesthetic appreciation of consonance. But we shall see later (Table IX) that those Elementary School children who did well in two of Stumpf's tests for a 'musical ear' (cf. p. 210) reached a stage of development equivalent to that of the adults at an earlier age than those who did badly in these tests. At least we can assume that a fairly keen discrimination both of pitch and of consonances from dissonances is necessary for a degree of general musical ability much above the average. Thus they would be selected together in at least one of the ways in which we may suppose the average musical

1 Of the seven children under eight years of age, three (two of seven years of age and one of six years) had not studied music. They showed scarcely any preference for concords over discords. The four who had studied music (three of seven years and one of six years) showed much more diserimination, the scores giving an average of nearly 0.5 per vote for the concords, and -0.2 for the discords. But these numbers are of course far too small to base any inference upon. Apart from this there is doubtless a tendency for the precociously musical child to begin lessons earlier than the others. From the eight-yearold son of a University Professor, well above the average in intelligence, and who had had no instruction in music, I was able to obtain four judgments upon each of the intervals. He showed practically no preference on the whole for concords (average vote 0.6 ) to discords (average vote 0.5 ). There was however a marked preference for the major and minor sevenths (average of each $+1 \cdot 0$, i.e. 'pleasing') to the major and minor seconds (average $-\cdot 25$ and $+\cdot 25$ respectively).

2 See this Journal, iII. 125. 
ability of the upper-middle classes to have been increased or maintained, and that of the lower classes comparatively lessened, namely by the selection and raising to a somewhat higher social standing of persons of marked musical ability in the lower-middle or working classes. Further speculation on this point is beyond the scope of this paper. But granted some difference in the musical sensitivity of the two social groups, few will doubt that their musical training was an important factor in determining the rapid advance in the Preparatory School children in the capacity to appreciate the difference between consonances and dissonances. One possible criticism must be dealt with. It may be suggested that to the young children who had had musical instruction the discords may have sounded 'wrong' without having any of the unpleasantness naturally associated with dissonance. But that implies a capacity for remembering and identifying an interval which the music mistress had frequently corrected, a capacity which is surely more surprising and improbable in young children than the feeling of the unpleasantness of a discord. Even a musical adult in these experiments mistook a major second, which he found pleasing, for one of the thirds, and was doubtful whether a pleasing minor seventh was not an octave. Nor do the reasons given by the children give any support to this suggestion. The only one who speaks of the notes 'sounding right' is an Elementary School boy of seven years who had not had music lessons.

\section{Tests for a 'musical ear.'}

At each sitting, after the playing of all the intervals and before they were repeated in the opposite order, other simple musical tests were given, similar to those used by Stumpf, for discriminating musical from unmusical individuals. In test $A$ the children were asked to say whether I was playing one or two notes on the piano. Three times two notes were played (the vetave, major third and tritone), three single notes being interspersed. In test $\mathrm{B}$, the children had to say whether the second of two notes, played successively, was higher or lower than the first. Three times the second note was higher, and three times lower than the first. In four cases the notes differed by a semitone and in two cases by a full tone. I first explained what higher and lower meant by playing a succession of ascending notes on the piano and saying that those were 'getting higher,' and similarly with a succession of descending notes. As test A is appreciably harder than B, especially 
to children unfamiliar with the piano, mistakes in A were only reckoned as half errors, those in B counting as full errors. In order to divide the children roughly into two equal groups, and to allow fully for 'slips' and misunderstandings, only those whose total errors were more than two were classed as 'unmusical.' 'The number of boys taking part in the experiments was 95 , the girls numbering 100 . Of these 37 boys and 43 girls were 'musical,' numbers that do not allow us to infer that either sex, at this age, is more 'musical', as far as these tests can indicate.

No marked correlation was observable between success in these musical tests and general intelligence, a result which encournges the belief that the task was explained clearly enough even for the duller children to understand. The numbers were as follows:

\section{Intelligent children.}

31 musical, 42 unmusical.

\section{Unintelligent children.} 26 musical, 38 unmusical.

Table IX shows the connexion between success in these tests, and the votes for the various intervals. As there are only four musical children of seven years we will ignore that column. An examination of the others shows that among the younger children (ages eight and nine) the musical ones are more critical throughout, but not more averse, proportionately, to discords than are the unmusical children. At ten years the musical children are slightly less critical both towards concords and discords.

Thus up to the age of eleven or thereabouts, the greater sensitivity of ear, as shown by the musical tests, does not result in greater discrimination of concord and discord. There is, on the average, a slightly more critical attitude towards all intervals, possibly the beginnings of an attitude in which the notes are no longer pleasing merely because they are sounds, an attitude perhaps more readily adopted by the child possessed of a more sensitive hearing (in a musical sense). But after eleven years the more 'musical' children are emphatically more averse to discords than are the 'unmusical,' though at least as appreciative of concords. The total scores for the discords (for thirty children) are $15 \cdot 3$ for the unmusical, but -89 for the musical children over eleven years of age. This marked correlation must mean either that a musical ear (as tried by Stumpf's tests) does eventually reveal itself also in greater sensitivity to the unpleasantness of discords, or that the two capacities, though not directly connected, are generally found together. No doubt familiarity with the piano would be one factor in determining success in Stumpf's 


\section{The Appreciation of Musical Intervals}

Table IX. Votes of 'musical' and 'unmusical' children.

\begin{tabular}{|c|c|c|c|c|c|c|c|c|c|c|c|c|c|c|}
\hline \multirow[t]{2}{*}{ Ages ...... } & \multicolumn{2}{|c|}{13} & \multicolumn{2}{|c|}{12} & \multicolumn{2}{|c|}{11} & \multicolumn{2}{|c|}{10} & \multicolumn{2}{|c|}{9} & \multicolumn{2}{|c|}{8} & \multicolumn{2}{|c|}{7} \\
\hline & 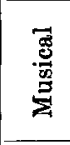 & 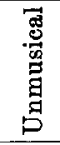 & 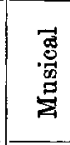 & 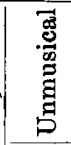 & 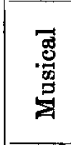 & 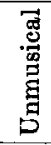 & 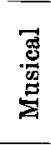 & 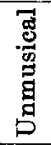 & 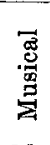 & 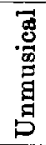 & 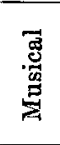 & $\begin{array}{l}\overrightarrow{\mathrm{D}} \\
\stackrel{0}{0} \\
\stackrel{g}{g} \\
\stackrel{g}{g}\end{array}$ & 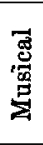 & 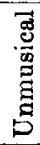 \\
\hline No. of children & 22 & 9 & 10 & 14 & 14 & 10 & 10 & 16 & 14 & 13 & 7 & 18 & 4 & 20 \\
\hline Major third & 32 & 6 & 14 & 12 & 23 & 10 & 12 & 18 & 10 & 22 & 8 & 29 & 6 & 24 \\
\hline Minor third & 22 & 4 & 10 & 4 & 16 & 13 & 8 & 26 & 16 & 22 & 7 & 22 & 4 & 24 \\
\hline Octave............. & 19 & 13 & 4 & 12 & 24 & 10 & 16 & 16 & 18 & 20 & 7 & 24 & 2 & 21 \\
\hline Major sixth...... & 27 & 7 & 8 & 12 & 16 & 16 & 12 & 16 & 16 & 22 & 3 & 26 & 2 & 16 \\
\hline Minor sixth..... & 24 & 14 & 2 & 18 & 12 & 8 & 12 & 18 & 10 & 16 & 8 & 22 & 2 & 27 \\
\hline Fourth $\ldots \ldots \ldots$ & -2 & 0 & 6 & 12 & 16 & 14 & 14 & 18 & 10 & 22 & 8 & 14 & 6 & 22 \\
\hline Tritone .......... & 11 & 1 & 0 & 4 & 10 & 4 & 11 & 10 & 16 & 14 & 5 & 18 & 6 & 26 \\
\hline Fifth $\ldots \ldots \ldots \ldots$ & 4 & 7 & 2 & -2 & 20 & 8 & 8 & 18 & 10 & 10 & 8 & 21 & 6 & 27 \\
\hline Major second... & -10 & 5 & 6 & -2 & -9 & 16 & 2 & 2 & 8 & 6 & -1 & 18 & 8 & 26 \\
\hline Minor seventh.. & 0 & 2 & -8 & 10 & -6 & 6 & 8 & 8 & 6 & 19 & $\overline{7}$ & 26 & 6 & 18 \\
\hline Major seventh.. & -22 & -4 & -10 & -4 & -18 & 2 & 4 & 4 & 12 & 7 & 8 & 14 & 2 & 22 \\
\hline Minor second... & -28 & -5 & -10 & -16 & -6 & 2 & $\mathbf{2}$ & 2 & 0 & 4 & 5 & 12 & 4 & 20 \\
\hline
\end{tabular}

Total votes, adjusted to represent votes of 10 children-

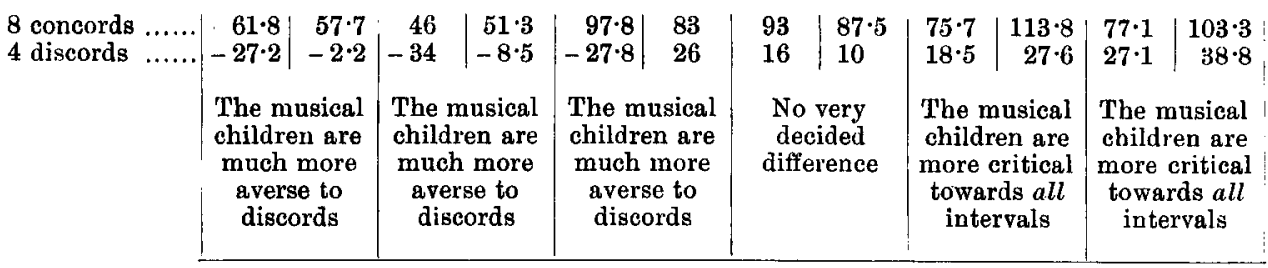

tests $^{1}$. If so, we should expect to find this correlation, on the assumption which we have already made, that the aesthetic appreciation of consonance is also developed by familiarity. But it is difficult to explain the inarked correlation among the older children by this familiarity with the instrument alone, for nearly all these Elementary School children gain their knowledge of pianoforte music largely from the school, where they have equal opportunities. Very few would have a piano in the home, and as we saw only 17 out of 195 were having music lessons.

It seems highly probable, then, that the musical sensitivity, as tried by Stumpf's tests, is closely connected with the aesthetic discrimination between consonance and dissonance, both doubtless being cultivated by

1 The same tests were given to the Preparatory School girls but only 7 of the 76 made a total of more than two errors, and 3 of these were only 7 years old. All of them, except one seven-year-old, were as averse to the discords as were the 'musical' children. 
familiarity with music. The average improvement in Stumpf"s tests is especially rapid up to, and including, the age of nine, as Gilbert found was the case with tone discrimination. That it is not accompanied by greater discrimination between concords and discords until a year or so later may signify that further musical experience is necessary before the improved capacity for discrimination (such as is involved in Stumpf's tests) can be brought to bear on the higher aesthetic appreciation of consonance or dissonance ${ }^{1}$.

\section{Introspection of school children.}

\section{(a) Elementury School children.}

Naturally the records were not rich in introspective remarks, although the children were asked to give their reasons for liking or disliking the intervals. Such terms as 'sweet,' 'good,' 'nice' were common with the youngest children. The first indications of the hearer's attention being attracted to the effect of the notes upon himself occur at the age of nine and are then concerned wholly with unpleasant effects, e.g. ' makes my head ache,' 'makes an awful sound in my ears,' 'makes my ears ring.' At the ages of eleven, twelve and thirteen we find more frequent judgments of this kind, and no longer confined to unpleasant effects, thus : 'pleasant to the ear,' ' soothing,' ' grating,' ' nice for singing to.'

Children over the age of eleven also make the comments 'bold,' ' cheery,' 'strong,' 'awful sad ' and 'uncanny.' Frequent references are made to the pitch of the notes as the following list shows.

Intervals said to be

A

Pleasing because high, by 15 boys and 15 girls
B

Pleasing because low, by 4 boys and 4 girls

\section{C}

Displeasing because too low, by 20 boys and 24 girls

$\mathrm{Six}$ of the eight children who find intervals pleasing because 'low' are over twelve years of age. In column $\mathrm{A}$, twenty-three of the thirty children were over ten years of age. In column $\mathrm{C}$, thirty-nine of the forty-four children were over ten, the numbers being fairly equally distributed (in the case of both columns $\mathrm{A}$ and $\mathrm{C}$ ) among the various ages from ten to thirteen. Thus the height of the pitch does not appear to effect the younger children any more than the older ones.

1 I do not think that anything said here is inconsistent with Mr T. H. Pear's criticism of these tests as adequate tests of general musical capacity (this Journal, IV. 89), with which I fully agree. Even the addition of a test for the appreciation of consonance and dissonance would not make a satisfactory test of the capacity to enjoy music, 
Some increase after the age of nine in the number of children who refer to height or lowness of pitch is only to be expected, as the children become more able, with increasing age, to give reasons for their likes and dislikes. The answers as a whole indicate that somewhat higher intervals would have been more pleasing to the children. The pitch used would be low for the children to sing, and some introspective remarks suggest that this is of considerable weight in determining the pleasingness of a note to a child.

The occurrence of associations is peculiar. They occur far more frequently about the ages of ten and eleven than either before or after those ages. Thus 106 associations out of 165 are given by chldren of ten or eleven years of age, i.e. nearly two-thirds of the associations are given by about one quarter of the children. Twenty-three boys give associations, but only thirteen girls, though the average number of associations given by these thirtcen is higher than that of the twenty-three boys 1 . Only two girls but ten boys under the age of ten give associations. These facts may indicate a greater interest on the part of young boys (compared with girls) in the sounds of objects suggested by the intervals, e.g. bells, clocks, motor horns, and one delightful expression of discord on the part of a small boy, "like in man smashing a tin can and he can't smash it any more."

(b) Preparatory School children.

Here the most striking fact is the absence of associations. In the 1824 judgments given by these children only one association occurred, 'like a bugle.' The principal cause undoubtedly lies in the high degree of musical training of these children. They never think of associating such sounds with anything but a piano, an instrument they know so well.

\section{Sex differences in the Elementary School experiments.}

We have already noted the more frequent occurrence of associations among the boys. Another marked difference is revealed by the total votes for and against the intervals. The boys are much more critical, the girls much more disposed to say 'I like it.' Thus the eight concords receive a balance of positive votes to the number of 879 from the 100 girls, but only 688 from the 95 boys. This characteristic difference is shown through all the ages. Table $\mathrm{X}$ shows the actual number of votes for the various ages.

1 Chiefly owing to the fact that one girl gave fourteen associations. 
TABLE X

\begin{tabular}{|c|c|c|c|c|c|c|c|c|c|c|}
\hline & \multicolumn{2}{|c|}{ Ages $6 \& 7$} & \multicolumn{2}{|c|}{ Ages $8 \& 9$} & \multicolumn{2}{|c|}{ Ages $10 \& 11$} & \multicolumn{2}{|c|}{ Ages $12 \& 13$} & \multicolumn{2}{|c|}{ All ages } \\
\hline & $\begin{array}{c}17 \\
\text { boys }\end{array}$ & $\begin{array}{c}22 \\
\text { girls }\end{array}$ & $\begin{array}{l}28 \\
\text { boys }\end{array}$ & $\underset{24}{24}$ & $\begin{array}{c}24 \\
\text { boys }\end{array}$ & $\begin{array}{c}26 \\
\text { girls }\end{array}$ & $\begin{array}{c}26 \\
\text { boys }\end{array}$ & $\begin{array}{c}28 \\
\text { girls }\end{array}$ & $\begin{array}{c}95 \\
\text { boys }\end{array}$ & $\begin{array}{l}100 \\
\text { girls }\end{array}$ \\
\hline $\begin{array}{r}\text { Balauce of votes } \\
\text { for } 8 \text { concords }\}\end{array}$ & 138 & 202 & 224 & 260 & 197 & 252 & 129 & 165 & 688 & 874 \\
\hline $\begin{array}{c}\text { Balance of votes } \\
\text { for } 4 \text { discords }\end{array}$ & 66 & 94 & 51 & 100 & 27 & -8 & -68 & -50 & 76 & 136 \\
\hline
\end{tabular}

In each column the boys and girls are distributed between the two ages (given at the head of the column) in similar proportions, except in the first column where there are 14 girls of seven years to 8 of six years, and only 10 boys of seven year's to 7 of six years.

The totals for all ages suggest that the boys as a whole discriminate or at least dislike the discords more than do the girls. But the difference is almost entirely traceable to the ages of eight and nine where it is very marked.

\section{Summary of results and conclusions.}

I. The apparent pitch of an interval is for most people determined approximately by the pitch of its higher note, and not of its lower note as has been previously asserted.

II. Of all the intervals used the major third was by far the must liked by adults. Then comes a group of four, viz. minor third, octave, major and minor sixth, which on the average are found 'pleasing.' Then a third group, the fourth, tritone and fifth, each on the average 'slightly pleasing.' This order, it will be observed, is by no means coincident with the order of degree of consonance.

III. The major third and major sixth are described as sad by adults twice as often as the minor third and minor sixth. This supports the view that the usual effects of the minor key for modern European ears are not due to any 'natural' effect of the minor intervals, but are determined by association.

IV. Even the highly consonant intervals of the fifth and fourth are sometimes described (by adults) as discordant.

V. Among the children in the Elementary Schools tested no appreciable preference for concords before discords is discernible before the average age of nine, at which age a considerable advance takes place. 


\section{6 The Appreciation of Musical Intervals}

VI. A group of children of the age of twelve or thirteen gives an order of preference for the twelve intervals within the octave, which is remarkably like that given by adults.

VII. No appreciable difference is discernible between the preferences of the more intelligent and those of the less intelligent children.

VIII. No correlation appears to exist between general intelligence and the capacity for such simple tests as comparing the pitch of two notes, or detecting whether one or two notes are being played on the piano at a time.

IX. Greater musical capacity, as measured by such tests, is correlated (but only after the age of eleven) with much greater aversion to discords.

X. Associations occur with musical intervals most frequently by fir at the ages of ten and eleven.

XI. More boys than girls have such associations. On the average boys are much more critical than girls towards musical intervals.

XII. The Preparatory School girls show an aversion to discords (except to the minor seventh) even at the ages of seven and eight, and about the age of nine they give, on the average, an order of preferences for the twelve intervals very similar to that given by adults. Thus, by the age of nine, they reach a stage of development only attained by the Elementary School children by the age of twelve or thirteen ${ }^{1}$.

1 My thanks are due to Dr C. S. Myers for a careful reading of this paper and for the suggestion of several emendations; also to Miss Preston, Headmistress of St Catherine's School, St Andrews; Mr J. Williamson, Headmaster of South Tay Street School, Dundee, and Mr A. Swinton, Headmaster of Balfour Street School, Dundee, for the facilities they kindly afforded me for testing their pupils in these experiments.

(Manuscript received 20 September, 1912.) 